\title{
Un Estudio desde la Ciencia Política de la Mediación en Centroamérica: El Caso de Costa Rica
}

\author{
Evelyn HERNÁNDEZ-ORTIZ \\ Universidad de Costa Rica \\ evelyn.hernandez.ortiz@gmail.com/evelyn.hernandez@ucr.ac.cr
}

Recibido: 04/06/2012

Aceptado: 13/11/2012

\begin{abstract}
Resumen
La mediación, como método de la resolución alternativa de conflictos, es un instrumento para la solución pacífica de conflictos y contribuye a generar un cambio en la conducta de las relaciones humanas, facilitando una mejor calidad de vida y promoviendo la paz social. La mediación es la intervención de un tercero neutral en un conflicto personal, comunitario, organizacional, económico, legal o político, con el propósito de que las partes en conflicto, resuelvan sus problemas y diferencias en un ambiente seguro.

Este trabajo analiza la vocación que ha tenido el sistema político costarricense en la resolución de conflictos. Este análisis se hace a partir de algunos elementos teóricos y de una breve reseña histórica sobre el proceso de paz en Centroamérica. Asimismo, estudia la vocación hacia la mediación que ha tenido el sistema político costarricense en la resolución de sus conflictos. Se estudia la forma en que el Tribunal Supremo de Elecciones (TSE), la Defensoría de los Habitantes, la Conferencia Episcopal de la Iglesia Católica y el Consejo Nacional de Rectores (CONARE), han intervenido como terceros, reconocidos como legítimos, por los actores no gubernamentales, que han necesitado de la ayuda de un tercero para resolver sus conflictos frente a determinadas políticas públicas elaboradas por el gobierno de turno. Se aborda también un punto de inflexión en el año 2007, fecha en que se presentó el primer referéndum en el sistema político costarricense, como alternativa para resolver el conflicto con motivo de la discusión del Texto del Tratado de Libre Comercio entre los Estados Unidos de América, Centroamérica y República Dominicana (DRCAFTA), ante la pérdida de legitimidad de algunos de los actores que habían sido históricamente quienes habían intervenido en la solución de conflictos.
\end{abstract}

Palabras clave: mediación, negociación, sistema político, grupos de interés, grupos de presión, política pública.

\section{A Political Science Study of Mediation in Central America: The Case of Costa Rica}

\begin{abstract}
Mediation is a method of alternative dispute resolution. It should be considered as an instrument for the peaceful resolution of conflicts that contributes to make a change in the conduct of human relations. It also provides a better quality of life and promotes social peace. Mediation is the inter-vention of a neutral third party in a conflict. The conflict could be in the community, it could be organizational, economic, legal or political. The third party (mediator) will intervene in order that the parties in conflict resolve their problems and differences in a safe environment.
\end{abstract}


This paper examines the mediation that the Costa Rican political system has used to resolve dis-putes. This analysis evaluates the theoretical elements, and it does a brief historical overview of the peace process in Central America. It studies the way in which the Supreme Electoral Tribunal, the Ombudsman, the Episcopal Conference of the Catholic Church and the National Council of Rectors (CONARE), intervened as third parties (mediatiors). They were recognized by non-governmental actors that needed help from a mediator to resolve their conflicts relating to certain gubernamental public policies developed by the current government. It also addresses a turning point in 2007, when was presented the first referendum in Costa Rican political system as an alternative to resolve the dispute in connection with the discussion of the text of the Free Trade Agreement between the United States of America Central America and Dominican Republic (DRCAFTA). This happened because of the loss of legitimacy of some parts, who historically had been involved in conflict resolution.

Keywords: mediation, negotiation, political system, interest groups, pressure groups, public policy

\section{Referencia normalizada}

Hernández-Ortiz, E. (2013). "Un Estudio desde la Ciencia Política de la Mediación en Centroamérica: El Caso de Costa Rica”. Política y Sociedad, Vol.50 núm. 1: páginas. 113-144

Sumario: Introducción. 1.La mediación en el marco del sistema político costarricense. 2.Antecedentes: Centroamérica, una región con vocación para la mediación. 3.Los actores legítimos en la resolución de conflictos en el marco del sistema político costarricense: análisis de dos casos relevantes. 4.Reflexión final. 5.Referencias bibliográficas

\section{Introducción}

La mediación pertenece a los métodos de resolución alternativa de conflictos (RAC) junto con la negociación y el arbitraje. Estos métodos de resolución alternativa de conflictos se refiere al conjunto de formas o procedimientos para resolver determinados conflictos o disputas, de manera diferente a las tradicionales; es alternativa porque la esencia de la resolución del conflicto radica en la negociación entre las partes, a diferencia de los procesos judiciales y se crean desde la perspectiva de que existen formas no adversariales y cooperativas para resolver disputas entre las partes.

La mediación se define como la intervención de un tercero neutral en un conflicto, con el propósito de ayudar a las partes a resolver sus problemas en un ambiente seguro. La persona mediadora mejora el proceso de comunicación ayudando a las partes a definir claramente su problema, a comprender los intereses de cada parte, y a generar opciones para solucionar la disputa. El mediador no impone una solución al problema, y son las partes quienes mantienen siempre la responsabilidad de tomar su propia decisión (Butts Griggs, et.al, 2009: 269)

De esta forma, la mediación es un proceso en el que una persona imparcial, facilita la comunicación entre dos o más personas en conflicto, con el propósito de lograr un acuerdo que resuelva sus diferencias, implica además, un proceso de comunicación entre las partes en conflicto con la ayuda de un mediador imparcial, 
que procura que las personas implicadas en una disputa puedan llegar, por ellas mismas, a establecer un acuerdo que permita reestablecer la buena relación y dar por terminado, o menos mitigado el conflicto; y que actúe preventivamente o de cara a mejorar las relaciones con los demás.

Por tanto, la mediación es un procedimiento no adversarial, pacífico y cooperativo de resolución de conflictos, que pretende lograr un acuerdo rápido y sin los costos en tiempo, dinero y esfuerzo de un proceso judicial

En el marco del funcionamiento del sistema político costarricense, hasta el año 2007, fecha en que se realizó el primer Referéndum en Costa Rica para definir el futuro del Texto del Tratado de Libre Comercio entre los Estados Unidos de América y República Dominicana (DRCAFTA) ${ }^{1}$, existía la tradición de que la solución negociada a los conflictos sociales, políticos y económicos que se presentaban entre el gobierno de turno y los sectores sociales, convertidos en la última década en grupos de presión, habían sido solucionados con la ayuda de representantes de el Tribunal Supremo de Elecciones (TSE), la Defensoría de los Habitantes, la Conferencia Episcopal de la Iglesia Católica ó el Consejo Nacional de Rectores (CONARE), según la naturaleza y los actores involucrados en el conflicto que surgía ante la formulación de una política pública.

En este sentido es oportuno recordar que debido a la naturaleza del sistema político costarricense, cuyas características lo ubican dentro del régimen presidencialista, no existe un proceso de formulación de decisiones establecido para la elabora-

${ }^{1}$ La celebración del primer Referéndum en Costa Rica el 7 de octubre de 2007 permitió dirimir un conflicto sobre el futuro del Texto del Tratado de Libre Comercio con los Estados Unidos de América y República Dominicana (DRCAFTA) que había producido en el sistema político costarricense una división maniquea entre los sectores que estaban a favor o en contra de este Tratado. Durante este período 2002-2007 algunas de las instituciones que habían sido protagonistas en los procesos de mediación tomaron una posición a favor o en contra de este tema de la agenda política nacional y se deslegitimaron para ser mediadores, por lo que se recurrió al Referéndum como forma para tomar una decisión que dirimiera el conflicto entre las dos posiciones. Sobre el particular, Juan José Sobrado, Presidente del Tribunal Supremo de Elecciones señala: “Tal y como finalmente quedó receptado el referéndum en nuestro medio, es claro que no está previsto como una apuesta por la democracia directa ni como instrumento para cuestionar la legitimidad del gobierno democráticorepresentativo. Se trata de un mecanismo de participación popular directa que complementa -y no enfrenta- el ejercicio representativo del gobierno, el cual será el que prevalezca respecto de la mayoría de las decisiones. La consulta al soberano es, en consecuencia, excepcional; a través de una adecuada regulación del instituto, es posible que ocasionalmente se active un saludable y democrático control popular del ejercicio del poder, para impedir que del seno del Estado constitucional emerjan subrepticiamente falsos poderes soberanos, con el beneficio adicional de propiciar valiosas oportunidades de educación e integración políticas”. Sobrado González, Juan José, "Primera Experiencia del Referéndum en Costa Rica: Regulación y Alcances”. Revista de Derecho Electoral. No. 4. Segundo Semestre 2007. Pp. 9. 
ción de las políticas públicas. En Costa Rica, el proceso de decisiones no es público, esto implica -en el nivel teórico- que no existen mecanismos en el inicio del proceso decisional que permitan que, desde el momento en que se toma la decisión por parte de los actores gubernamentales, intervengan otros actores no gubernamentales, sino que éstos toman una posición a favor o en contra, y actúan como grupos de interés o grupos de presión una vez que la decisión ha sido tomada. Un elemento adicional es que en los últimos años el concepto sociedad civil y su margen de maniobra por su capacidad de organización en el sistema político costarricense ha tomado una relevancia sobre cualquier política pública.

Este trabajo analiza el papel como mediadores de los representantes del Tribunal Supremo de Elecciones (TSE), la Defensoría de los Habitantes, la Conferencia Episcopal de la Iglesia Católica y el Consejo Nacional de Rectores (CONARE), en la solución de conflictos que se presentaron ante la formulación de una política pública en la gestión de diferentes gobiernos dentro del sistema político costarricense.

\section{La mediación en el marco del sistema político costarricense}

Costa Rica a diferencia del resto de los países centroamericanos ha contado con una tradición democrática y de justicia social que ha permitido un mayor desarrollo económico, social y político. El Poder Judicial fue la institución responsable de liderar las acciones para dar forma al sistema de resolución alterna de conflictos que se institucionalizó en el país hasta la actualidad. A inicios de la década de los años noventa se firma un convenio con la Agencia Internacional de Desarrollo (AID), en el cual se establece como una de las áreas prioritarias el desarrollo de la resolución alterna de conflictos; y en 1998 se promulgó la Ley 7727: Ley de Resolución Alterna de Conflictos y Promoción de la Paz Social que regula los elementos referentes a la conciliación, a la mediación y al arbitraje.

En la actualidad, la resolución alternativa de conflictos se gestiona en Costa Rica mediante la Dirección Nacional de Resolución Alterna de Conflictos, que es una dependencia del Ministerio de Justicia y Paz, cuyos objetivos son: impulsar el conocimiento y desarrollo en la aplicación de los métodos alternos de resolución de conflictos, controlar y fiscalizar a los centros autorizados para dedicarse a la administración institucional de métodos RAC, acercar la justicia a las comunidades y fortalecer el Programa de Casas de Justicia, a fin de brindar acceso gratuito a la mediación o conciliación extrajudicial ${ }^{2}$.

${ }^{2}$ El programa de Casas de Justicia se inauguró en el año 2000, con la finalidad de descongestionar los procesos judiciales y a la vez brindarle a la población la posibilidad de resolver los conflictos de una forma muy pacífica, es decir a través del diálogo y con un enfoque basado en los intereses de las partes que llevan a cabo un proceso de mediación, en 
La Ley 7727: Ley de Resolución Alterna de Conflictos y Promoción de la Paz Social ha permitido el desarrollo tanto de centros privados de conciliación y arbitraje, como de casas de justicia que trabajan de manera conjunta con universidades y municipalidades. Las casas de justicia se dedican a la administración institucional de la mediación comunitaria, con el propósito de coadyuvar con la gestión de un facilitador (mediador) para encontrar una solución al conflicto existente, mediante la libre voluntad y acuerdo entre las partes en controversia.

Estas iniciativas pretenden construir y promover una cultura para la paz mediante la resolución pacífica de los conflictos y parten de la premisa de que las dinámicas que se desarrollan mediante estos métodos sean lo más transparentes posibles para fortalecer la democracia.

La búsqueda de esa "cultura para la paz” y el papel de los métodos de resolución alterna de conflictos en un sistema político, implica el análisis y la solución del conflicto y de los problemas que lo causan como un proceso de cambio en los sistemas social, político y económico, que debería tener en cuenta las necesidades individuales y de grupo, al mismo tiempo que se fortalezcan los cambios institucionales necesarios para satisfacer las necesidades. Si la cultura para la paz y la importancia dada a los métodos de resolución alternativa de conflictos fueran parte del proceso de socialización de la ciudadanía en cualquier sistema político, se fortalecería la estabilidad política y la institucionalización en la resolución de conflictos.

Este trabajo comprende el sistema político a partir de la definición que presenta Maurice Duverger que señala, estudiar un sistema político no es solamente analizar sus instituciones políticas y su disposición coordinada como régimen político. Es también estudiar las relaciones entre este régimen y los demás elementos del sistema social: económicas, técnicas, culturales, ideológicas, históricas, etc. En este sentido, llamamos sistema político al conjunto del sistema social, estudiado bajo la perspectiva de sus aspectos políticos. Tal enfoque se justifica por el hecho de que el sistema político es el cuadro general del sistema, en el que sus diferentes elementos se ordenan unos a otros. Se comprenden mejor sus interacciones y la articulación general del sistema social si se le contempla bajo su aspecto político (Duverger, 1988: 33)

De esta forma, para enmarcar la importancia de los métodos de resolución alternativa de conflictos en el sistema político costarricense, se trasciende la definición de régimen político y se utiliza un enfoque que involucra la interacción entre las instituciones formales del régimen político y los actores gubernamentales y no gubernamentales, con el propósito de dilucidar el papel de la mediación en la solu-

donde con ayuda de una tercera persona imparcial logran plantear soluciones a sus conflictos mejorando de esta forma la convivencia. Para más información sobre las Casas de Justicia y los Centros RAC que operan en Costa Rica, consúltese:

http://culturadepaz.mjp.go.cr/index.php?option=com_content\&view=article\&id=44\&Ite mid=55\&lang=es Consultada el 10 de Octubre de 2011: 9:45 a.m. 
ción de los conflictos, bajo la premisa de que las relaciones régimen - sociedad están en relación con la lógica de eficacia y legitimidad que producen las decisiones gubernamentales en los valores y en la acción de los individuos y grupos sociales que constituyen la sociedad en la comprensión de la actividad política.

La mediación constituye un procedimiento no adversarial y pacífico de resolución de conflictos, tendiente a lograr un acuerdo rápido y económico en términos de tiempo, dinero y esfuerzo, objetivo difícil de conseguir cuando los conflictos deben dirimirse en una sede judicial. Asimismo, también se puede definir como un sistema de negociación asistida, mediante el cual las partes involucradas en un conflicto intentan resolverlo por sí mismas, con la ayuda de un tercero imparcial que actúa como favorecedor y conductor de la comunicación. Los interesados asumen su protagonismo en la búsqueda de alternativas posibles de solución y controlan por sí mismas el proceso cuyo desarrollo es rápido e informal. La decisión a la que eventualmente lleguen las partes es elaborada por ellas mismas y no por un tercero, como en el caso de un pronunciamiento judicial. Es un proceso donde no existen ganadores ni perdedores, pues todos los interesados se benefician de los acuerdos que se logren; y evita que las relaciones personales se deterioren o destruyan como consecuencia de la tramitación de prolongados juicios y por tanto, es un mecanismo que permite aumentar la paz social entre los ciudadanos.

La tradición democrática y de justicia social que ha caracterizado al sistema político costarricense, ha tenido sus puntos de ruptura en diferentes gobiernos a partir del año dos mil, producidos por las decisiones en la elaboración de las políticas públicas que emanan de las distintas instituciones del Poder Legislativo o del Poder Ejecutivo, lo cual ha provocado manifestaciones de sectores sociales, grupos de interés que se convierten en grupos de presión ante la insatisfacción de las demandas producidas por la decisión de las instituciones del régimen político y la elaboración de políticas públicas que desde el punto de vista de estos grupos, deterioran la democracia. En este sentido, debido a que una política pública es el resultado de una autoridad investida de poder público y de legitimidad gubernamental (Meny y Thoenig, 1992: 89), la elaboración y ejecución de esta política pública tiene efectos sobre los actores no gubernamentales afectados por la misma, que pueden implicar procesos de negociación formales o informales, entre actores gubernamentales y no gubernamentales, o bien, entre representantes de instituciones públicas y actores privados que, por contraposición, no tienen competencia formal o capacidad institucional para la adopción de decisiones colectivas, pero que tienen capacidad de reacción ante el efecto de una determinada política pública. Este último escenario es lo que ha provocado la necesidad de que algunos actores propios del sistema político costarricense, tales como el Tribunal Supremo de Elecciones, la Defensoría de los Habitantes, la Conferencia Episcopal de la Iglesia Católica y el Consejo Nacional de Rectores (CONARE), que han sido reconocidos como legítimos, neutrales e imparciales, coadyuven en la solución de un conflicto, tal como lo demanda un proceso de mediación.

En este sentido, debe recordarse que la mediación es un proceso voluntario, libre, pacífico y directo de las partes involucradas en el conflicto y sobre todo, las caracte- 
rísticas de una persona mediadora están vinculadas con su capacidad para ayudar a las partes en conflicto a encontrar una solución; es una experta en el arte de devolver a las partes su capacidad negociadora, de permitirles que recuperen la posibilidad de gestionar su conflicto ellas mismas, acordando soluciones inteligentes y beneficiosas. Además, la misión de la persona mediadora es propiciar, estimular, escuchar y dar guía a las partes para que ellas mismas encuentren y logren una solución satisfactoria al problema que origina el conflicto; a diferencia del juez o árbitro, el mediador no decide, ni declara alguna resolución de la controversia o conflicto, por cuanto no deriva alguna autoridad, ni impone solución sobre los intereses que las partes resuelven.

En síntesis, el mediador no asume en ningún caso el protagonismo, que corresponde únicamente a las partes en conflicto; actúa desde la ausencia de autoridad y poder. Los procesos de mediación deberían ser de carácter libre y voluntario, al margen de toda intervención de jueces y abogados en ejercicio como tales (Vinyamata Camp, 2003: 17).

El reconocimiento legítimo por parte de los actores no gubernamentales sobre los representantes de las instituciones que han tenido una vocación hacia la mediación en los conflictos presentados en el marco del sistema político costarricense, complementa el hecho de que el proceso de elaboración de toda política pública implica decisiones e interacciones entre individuos, grupos e instituciones, decisiones e interacciones influenciadas sin duda por las conductas, las disposiciones del conjunto de individuos, grupos y organizaciones afectadas (Subirats, 1992:10). Estas decisiones e interacciones entre los actores gubernamentales y no gubernamentales en torno a un política pública puede producir procesos de negociación o una escalada de conflicto que, por las características del sistema político costarricense, se manifiesta en la intervención que ejercen los grupos de interés sobre el mecanismo gubernamental para imponer sus reivindicaciones o aspiraciones para influir sobre formulación de la política pública, o bien en las acciones que imponen los grupos de presión cuando actúan y ejercen presión sobre la esfera gubernamental. Una de las características generales del sistema político costarricense, a partir del año 2000, ha estado constituida por una tendencia a la formación de asociaciones o movimientos que representen o pretenden representar un sector determinado. Asimismo, la calidad de los dirigentes como líderes de opinión y la amplitud de relaciones que han logrado constituir dentro de la Asamblea Legislativa y en los Ministerios que tratan determinados asuntos de la agenda política nacional que son de su interés particular, así como en los medios de comunicación, son elementos que influyen en la eficacia de las acciones que puede desarrollar un grupo ante una determinada política pública que afecte sus intereses y los intereses nacionales.

Es importante tomar en consideración que los procesos de negociación no existen en el imaginario colectivo de la ciudadanía costarricense, por el contrario, ante cualquier política pública que lesione las demandas de un determinado grupo o sector, los líderes de opinión llaman a ejercer acciones de presión como manifestaciones, marchas, huelgas o bloqueos, y en este sentido, los medios de comunicación coadyuvan con tales acciones. 
De la misma manera, se ha presentado una tradición de pactos políticos entre los partidos mayoritarios, tanto en acuerdos entre su líderes, como en los acuerdos que se presentan entre las diferentes fracciones representadas en la Asamblea Legislativa, particularmente, a partir del año 2002 que se presentó un cambio de un sistema de partidos bipartidista, hacia un sistema multipartidista en la representación del Poder Legislativo y que es un fenómeno que se ha venido consolidando hasta el presente. De esta forma, en las últimas elecciones realizadas a partir de 2002, al Poder Ejecutivo la ha correspondido ejercer su gestión con un gobierno dividido, presidentes sin mayoría en el Poder Legislativo- lo cual ha contribuido al bloqueo parlamentario y ha influido en la canalización de conflictos políticos, así como en la consolidación o erosión de la gobernabilidad del sistema ${ }^{3}$.

Estos conflictos sociales y políticos que implican la intervención de un tercero neutral y que se produzca un proceso de mediación, se caracterizan por ser de carácter coyuntural, sin embargo quiebran la estabilidad institucional en el funcionamiento del sistema político costarricense, y fomentan, al final del camino, un diálogo social que promueve la reconciliación del sistema político con la ciudadanía costarricense. Lo anterior demuestra un aumento en las acciones de los sindicatos, asociaciones solidaristas y otros actores de la sociedad civil con capacidad de veto ante una política pública.

Como se mencionó anteriormente, las instituciones reconocidas con legitimidad y credibilidad ante la población costarricense, hasta la aprobación del Texto del DRCAFTA, en la solución de conflictos en temas de la agenda política nacional están representadas por el Tribunal Supremo de Elecciones, la Defensoría de los

\footnotetext{
${ }^{3}$ Costa Rica, al igual que todos los sistemas presidencialistas, carece de los medios para asegurar que el presidente cuente con el apoyo de una mayoría parlamentaria. Dado que los presidentes son electos en forma independiente de la asamblea, y debido a que las cualidades personales con frecuencia son decisivas en las campañas presidenciales, el ganador no necesita provenir de un partido mayoritario -si es que hay alguno-. En algunos países, los partidos de los presidentes no controlan nada que se acerque a la mayoría de los escaños en el Congreso. A veces resultan elegidos presidentes que disfrutan de un escaso apoyo en el Congreso, lo cual puede fácilmente conducir a amargas luchas entre el Ejecutivo y el Legislativo. Mainwaring, Scott \& Shugart Soberg, M. "Presidencialismo y democracia en América Latina: revisión de los términos del debate”. En: Mainwaring, Scott y Shugart Soberg, Mathew. (2002): Presidencialismo y democracia en América Latina. (ed.) Paidós, Buenos Aires. P. 38. En las últimas elecciones, a partir del año 2002, la elección del Directorio Legislativo había quedado bajo el control del oficialismo del partido de turno en el Ejecutivo, sin embargo, el pasado $1^{\circ}$ de Mayo de 2011 no fue posible lograr ningún acuerdo por parte de la fracción del oficialismo y fue elegido por todos los legisladores miembros de los partidos de oposición al Gobierno de la República de la Presidente Laura Chinchilla Miranda (2010-2014), un Directorio Legislativo constituido en su totalidad por miembros de partidos de oposición.
} 
Habitantes, la Conferencia Episcopal de la Iglesia Católica, y el Consejo Nacional de Rectores -que agrupa a las universidades públicas-.

\section{Antecedentes: Centroamérica, una región con vocación para la mediación}

El modelo de maduración del conflicto ${ }^{4}$, elaborado por el Profesor William Zartman, permite la convergencia de dos de los principales métodos de resolución alternativa de conflictos: la negociación y la mediación. Este modelo propone que un negociador debe de ser mediador de su propio conflicto y afirma que el mayor engaño sobre las negociaciones es presentar el fenómeno como eventos cortos, en lugar de momentos sucesivos en un contexto que evoluciona, dado que un conflicto se comprende como parte de un proceso general de maduración con los componentes de poder e interés de las partes involucradas en el proceso de negociación.

La firma del documento "Procedimiento para establecer la paz firme y duradera en Centroamérica”, el 7 de agosto de 1987 por parte de los cinco presidentes de los países centroamericanos, Oscar Arias Sánchez, Presidente de Costa Rica, José Napoleón Duarte Fuentes, Presidente de El Salvador, Vinicio Cerezo Arévalo, Presidente de Guatemala, José Azcona Hoyos, Presidente de Honduras y Daniel Ortega Saavedra, Presidente de Nicaragua, en Ciudad de Guatemala, constituyó un punto de ruptura en la historia política de la región centroamericana y un punto de

${ }^{4}$ El modelo de maduración del conflicto está constituido por tres etapas: diagnóstico, construcción de la fórmula de acuerdo y acuerdo sobre los detalles para ejecutar la fórmula general sobre los puntos específicos del conflicto. El diagnóstico es el proceso mediante el cual, las partes involucradas evalúan el problema que pretenden negociar para definir si es negociable o no. Uno de los objetivos del diagnóstico es determinar si el problema está listo para lograr una solución, y convocar a negociaciones formales para crear una agenda de negociación. El diagnóstico incluye una posibilidad de llegar a un acuerdo sobre los temas de la agenda, de manera que permita a las partes llegar a acuerdos parciales. La fórmula implica la definición conjunta del conflicto por las partes involucradas en la negociación, en términos susceptibles de una solución y debe proporcionar un marco general de referencia, en el cual, sea posible llegar a una solución mutuamente aceptable. W. Zartman señala que en las fórmulas de acuerdo, los intereses de las partes involucradas deben ser entendidos claramente y ajustarse en un entendimiento común de los problemas y de su solución -una fórmula puede expresar el problema dentro de una noción común de justicia y proveer una guía para ejecutar los detalles.

La culminación del proceso de maduración es el surgimiento de una fórmula de resolución. El proceso de maduración está determinado por el aprendizaje y la percepción de las partes involucradas en la negociación, para reconocer o crear el momento de maduración del conflicto; éste se asocia con las condiciones en las cuales, las partes involucradas realizan esfuerzos para resolver el problema y alcanzar sus objetivos “a un precio aceptable”. Zartman, William and Maureen R. Berman.(1982): The Practical Negotiator. New Haven and London Yale University Press, Massachusetts. 
encuentro en cuanto al consenso y aceptación unánime de los presidentes de la región sobre las propuestas y fórmulas de solución que se habían identificado.

Los presidentes lograron articular sus intereses y posiciones en torno a un acuerdo de paz, sin la influencia de otros actores que habían tenido un protagonismo en el conflicto la región, de esta forma fue posible alcanzar el consenso sobre la paz en Centroamérica por la voluntad política de todos los Presidentes de la región y el cumplimiento del acuerdo se materializó gracias a la voluntad, decisión y perseverancia de los representantes de los cinco países.

Sin duda alguna, los países centroamericanos, en la figura de los Presidentes de cada uno de los países centroamericanos que constituyen unidades última de decisión, asumieron un papel protagónico y exclusivo en la solución del conflicto y el Acuerdo de Paz permitió la identificación de un camino para la estabilización de la crisis en Centroamérica; fue el marco para el desarrollo de procesos de negociación entre diferentes actores y en diversos escenarios y aseguró la consolidación del proceso de pacificación, mediante la presencia de mecanismos operativos en el proceso como las reuniones de presidentes de la región en las denominadas Cumbres Presidenciales, que permitieron la legitimidad a los temas tratados y las decisiones adoptadas en el más alto nivel; y la Comisión Ejecutiva, constituida por los Cancilleres de cada país y que se caracterizó por ser una instancia de coordinación y ejecución de los acuerdos que tenían su origen en las Cumbres Presidenciales, así como la disposición de un calendario de ejecución de compromisos para que los Cancilleres reglamentaran, impulsaran y viabilizaran el cumplimiento de los acuerdos contenidos en el documento "Procedimiento para establecer la paz firme y duradera en Centroamérica”, y organizaran las comisiones de trabajo para el cumplimiento de los compromisos contraídos dentro de los plazos establecidos y la evaluación del proceso.

Los Acuerdos de Paz establecieron los siguientes temas en la agenda de trabajo conjunto entre los países de la región centroamericana: Reconciliación Nacional; Exhortación al cese de hostilidades; Democratización; Elecciones Libres; Cese de ayuda a las fuerzas irregulares o a los movimientos insurreccionales; No uso del territorio para agredir a otros estados; Negociaciones en materia de seguridad, verificación, control y limitación de armamento; Refugiados y desplazados; Cooperación, democracia, libertad para la paz y desarrollo; Verificación y seguimiento internacional; y Calendario de ejecución de compromisos, todos ellos importantes para devolver la estabilidad política a la región y consolidar el proceso de paz.

Es importante señalar que en las disposiciones finales del documento, desde el punto de vista de la premisa de que un buen negociador debe ser mediador de su propio conflicto, los Presidentes establecieron que los puntos contenidos en el documento formaban un todo armónico e indivisible. La firma del documento también estableció la obligación, aceptada de buena fe, de cumplir de manera simultánea lo que se había acordado en los plazos establecidos, y reiteró la voluntad política de consolidar un proceso de paz en la región centroamericana.

En las democracias postautoritarias es imperativo el surgimiento de una cultura política, entendida en este caso como un conjunto de principios normativos, de 
actitudes positivas derivadas de las experiencias negativas que el conflicto estimuló, tales como la adhesión a los valores de la tolerancia ideológica y política, la utilización permanente del recurso al diálogo y a la concertación, el rechazo elemental al uso de la fuerza y la discrecionalidad, el respeto hacia los derechos humanos y el repudio a todas las prácticas clientelísticas (Torres-Rivas, 2002: 141).

En resumen, la firma de los Acuerdos de Paz alcanzaron los siguientes resultados: la estabilidad para la región centroamericana, la adopción de decisiones políticas y compromisos adquiridos al más alto nivel; el compromiso de respetar el contenido de los acuerdos, procedimientos y la proyección hacia el futuro; la operacionalización de los acuerdos para su cumplimiento y seguimiento; y la incorporación de diferentes actores de la sociedad civil, reconocidos legítimamente.

Estos Acuerdos también representaron una convicción básica sobre los requerimientos de la Democracia y el Desarrollo de la región; la certeza de que la solución debía ser regional y sobre los intereses propios y no ajenos; permitieron comprender que se trataba de un proceso de mediano y largo plazo para fortalecer la capacidad política e institucional para resolver el conflicto y no de un fenómeno de carácter coyuntural, y sobre todo, permitieron convertir los Acuerdos en una política de Estado, con el compromiso de que debía perdurar en el tiempo. Todo lo anterior, legitimado por la firma y voluntad de los cinco Presidentes de la región centroamericana.

\section{Los actores legítimos en la resolución de conflictos en el marco del sistema político costarricense: análisis de dos casos relevantes}

\subsection{La sociedad civil frente al Proyecto de Ley para el Mejoramiento de los Servicios Públicos de Electricidad y Telecomunicaciones y la participación del Estado - Expediente 13873 “Combo Eléctrico" del 20 de marzo a 4 de abril de 2000}

El 20 de marzo del año 2000 fue aprobado en la Asamblea Legislativa, durante la Administración Rodríguez Echeverría (1998-2002), el Proyecto de Ley para el Mejoramiento de los Servicios Públicos de Electricidad y Telecomunicaciones y la participación del Estado - Expediente 13873, conocido popularmente como "Combo Eléctrico", debido a que fue el resultado de una fusión de otros tres proyectos de ley: "Ley de modernización y transformación del Instituto Costarricense de Electricidad” (expediente 12695), “Ley de generación de electricidad” (expediente 12693), y la "Ley general de telecomunicaciones" (expediente 12694).

El objetivo de este Proyecto era abrir a la inversión privada los mercados de energía y telecomunicaciones y dividir al Instituto Costarricense de Electricidad (ICE) en dos empresas especializadas regidas por el derecho privado.

La aprobación de este Proyecto hizo que se presentaran diversas manifestaciones en el sistema político costarricense por parte de diferentes actores y sectores de la 
sociedad civil que se oponían a esta iniciativa. Luego de la aprobación del denominado Combo Eléctrico hubo una serie de protestas simultáneas en varios puntos del país y con múltiples actores: agricultores, estudiantes, intelectuales, sindicalistas, empleados públicos, muelleros, ecologistas y organizaciones comunales, entre otros, que nunca antes se habían producido en torno a una iniciativa legislativa.

Esta decisión provocó un conflicto entre el 20 de marzo del 2000, fecha de aprobación en Primer Debate del Proyecto de Ley de Mejoramiento de los Servicios de Energía y Telecomunicaciones y de la Participación del Estado, por parte de 45 diputados de las fracciones de los partidos mayoritarios representados en la Asamblea Legislativa ${ }^{5}$, y el 30 de marzo del 2000, cuando se da a conocer un comunicado a la opinión pública por parte de la entonces Defensora de los Habitantes, Sandra Pisk; los entonces Rectores de las Universidades Públicas, Gabriel Macaya, Universidad de Costa Rica (UCR); Alejandro Cruz, Instituto Tecnológico de Costa Rica, (TEC), Rodrigo Arias, Universidad Estatal a Distancia (UNED); y Jorge Mora, Universidad Nacional (UNA); así como un representante de la Iglesia Católica, Monseñor Francisco Ulloa -que además, fue legitimado por la Conferencia Episcopal-, se ofrecieron a conformar una instancia facilitadora de un primer encuentro sin condiciones, entre los sectores involucrados, para definir un diálogo estructurado y un proceso que cumpliera con un acuerdo para las partes, y particularmente, que reestableciera la institucionalidad democrática dentro del sistema político costarricense.

Luego de un periodo de doce días de manifestaciones, bloqueos y protestas ininterrumpidas en las vías más importantes del país, y de una sociedad civil con una capacidad de movilización muy efectiva, que inició a partir de la aprobación del Proyecto de Ley y con un ambiente de tensión que rodeaba a la Asamblea Legislativa, las reacciones no se hicieron esperar. La aprobación ocurrió en medio de un ambiente de tensión, con el edificio del Congreso custodiado y tomado por centenares de policías armados con bombas lacrimógenas y equipos antimotines, mientras frente a la entrada principal cientos de estudiantes, trabajadores y sindicalistas, apostados allí durante todo el día, coreaban consignas de protesta.

Los adversarios del denominado "combo" energético anunciaron la intensificación de medidas de presión tendientes a evitar que la iniciativa fuera reafirmada en segundo debate. Expresaron ante la opinión pública que realizarían paros de labores

\footnotetext{
${ }^{5}$ El proyecto fue apoyado por los diputados del Partido Unidad Social Cristiana (PUSC) y del Partido Liberación Nacional (PLN). Votaron en contra los diputados José Merino, Célimo Guido y José Manuel Núñez, de Fuerza Democrática; el representante del Movimiento Libertario, Otto Guevara; del Partido Acción Laborista Agrícola, Guido Vargas; de Renovación Costarricense, Justo Orozco, y del Partido Integración Nacional, Walter Muñoz. A ellos se sumaron los liberacionistas Ricardo Sancho, Walter Robinson y Manuel Larios. En la sesión, que empezó a las 10 a. m., estuvieron ausentes el socialcristiano Luis Fishman y el verdiblanco Jorge Luis Villanueva. La Nación, 21 de Marzo de 2000. P. 3.
} 
en universidades estatales, muelles de Limón e instituciones autónomas como Acueductos y Alcantarillados (AyA) e Instituto Nacional de Seguros (INS) (La Nación, 21 de marzo, 2000) y en un segundo momento, varios sindicatos con una amplia capacidad de convocatoria en el país, anunciaron más protestas. Fueron días de mucha tensión dentro del sistema político costarricense, particularmente porque las manifestaciones y bloqueos precisaron de la acción policial para eliminar los obstáculos ubicados por los manifestantes para interrumpir el libre tránsito de personas y vehículos. En algunos momentos, la acción policial fue combinada con violencia entre los manifestantes y la policía, mediante el uso de gases lacrimógenos y policías antimotines, lo que dio como resultado personas heridas y arrestadas, lo cual no es común dentro del funcionamiento del sistema político nacional.

Mientras otros líderes de opinión políticos y religiosos llamaban a la calma, la paz social y al respeto de los derechos humanos; otros coincidían en que el Gobierno debería de tomar en consideración las demandas de las personas que se manifestaron en contra de la aprobación del "Combo Energético", sin embargo, las protestas en contra de la aprobación, en primer debate, de la Ley Combo Eléctrico, agrupó demandas insatisfechas y permitió expresar inconformidades y frustraciones de amplios grupos sociales contra el gobierno y la clase política, pospuestas o ignoradas durante años (La Nación, 27 de marzo, 2000), que generaron una escalada del conflicto sin precedentes en el nivel nacional.

Por su parte, el Gobierno estableció una comisión interinstitucional con el propósito de atender las propuestas, vigilar las áreas de conflicto y levantar los bloqueos y los diputados del Partido Liberación Nacional, condicionaron su voto en segundo debate a intensificar una campaña de información sobre el proyecto de ley.

El 31 de marzo los Rectores de las universidades públicas, la Defensoría de los Habitantes y la Iglesia Católica lanzaron una convocatoria a dialogar sin condiciones sobre el denominado "Combo Eléctrico", y en un segundo momento, el grupo facilitador invitó a representantes del Poder Ejecutivo, el Congreso, representantes de movimientos sociales, de grupos ambientalistas, de federaciones de estudiantes universitarios y del sector privado con el propósito de realizar un diálogo en el edificio del Tribunal Supremo de Elecciones. Es oportuno señalar que esta iniciativa contó con el aval del Gobierno y los sindicalistas

El Informe de labores de la entonces Defensora de los Habitantes, Sandra Piszk, señala, que los sectores en conflicto privilegiaban en su mayoría la opción del diálogo, y que existía una buena disposición para abrir espacios de acercamiento. El 30 de marzo, la Comisión integrada por la Iglesia, los Rectores y la Defensoría ofreció constituirse en "Una instancia facilitadora de un primer encuentro, sin condiciones, entre los sectores involucrados, para la definición de una agenda con miras al establecimiento de un diálogo estructurado, respetuoso, transparente y propositivo del cual emerjan las alternativas de solución que el país espera y merece" (Piszk, 2000: 6).

Efectivamente, el 4 de abril de 2000 hubo una respuesta positiva a la convocatoria de la Comisión Facilitadora, los representantes de los diferentes sectores se reunieron en las instalaciones del Tribunal Supremo de Elecciones, por ser una 
institución representativa de la democracia costarricense, y se convocó a cinco representantes del Gobierno de la República, un representante del Directorio de la Asamblea Legislativa, los Jefes de Fracción de los partidos políticos representados en el Congreso, cinco representantes del Frente Interno de Trabajadores del ICE (FIT), cinco representantes de grupos ambientalistas, cinco representantes de las federaciones estudiantiles de las universidades públicas y 5 representantes de la empresa privada.

La Comisión Facilitadora, convocó al diálogo nacional a las 9:00 a.m. del 4 de abril y a las 9:40 a.m. se inició el proceso de mediación, se definieron los mecanismos y objetivos, y para garantizar la transparencia del proceso se conceptualizó como una sesión abierta a la prensa y fue transmitida en directo por el Canal 13 del Sistema Nacional de Radio y Televisión (SINART), el objetivo propuesto fue "conocer y analizar propuestas sobre un mecanismo que permita de inmediato la realización de un diálogo nacional estructurado sobre el fondo y la tramitación del proyecto de modernización y transformación del ICE.” Asimismo, se estableció que el encuentro había sido cuidadosamente analizado por la Comisión teniendo presente que el clima de conflicto social que transitaba el país merecía que todas las personas y sectores involucrados comprendieran la necesidad de dar un primer paso en la dirección del diálogo y la convivencia pacífica (Piszk, 2000: 6).

La Comisión Facilitadora fue reconocida como legítima por las diferentes partes debido a la credibilidad de las instituciones que la conformaron, así como a la neutralidad e imparcialidad de las personas que la participaron en la misma, dos aspectos esenciales en un proceso de mediación. Además, debido a la escalada del conflicto en el nivel nacional, todas las partes coincidían en la necesidad de una salida negociada; se realizó en un lugar neutral con una mesa redonda que aseguró la igualdad entre todas las partes; la convocatoria fue pública y se establecieron con claridad las "reglas del juego" durante el proceso de mediación, a través de un reglamento que permitió que todas las partes expresaran sus posiciones e intereses para identificar soluciones o fórmulas de acuerdo sobre el futuro del "Combo Eléctrico".

La Comisión Facilitadora validó previamente la disposición de los actores involucrados a participar en el proceso de diálogo y les solicitó el nombramiento de representantes de los diferentes sectores de la sociedad civil y la designación de un vocero, lo cual convirtió a los asistentes al proceso de mediación en representantes legítimos de sus grupos con capacidad y autoridad para llegar a acuerdos. En el caso de los representantes del Poder Ejecutivo y Legislativo, su autoridad y legitimidad provenía de haber sido electos mediante la elección popular y ser jefes de las fracciones representadas en el Congreso, respectivamente.

De esta manera, también se validó, desde el punto de vista de la mediación, que este proceso fuera voluntario, pacífico y cooperativo entre las partes para la resolución del conflicto sobre un tema único que había desbordado la agenda política nacional, la institucionalidad del sistema político costarricense y que había servido como catalizador para que la sociedad civil demostrara su capacidad de organización y movilización. 
Además, como técnica del proceso de mediación, se realizaron reuniones separadas en diferentes lugares del Tribunal Supremo de Elecciones entre los diferentes actores que representaban las posiciones a favor o en contra del "Combo Eléctrico", con el propósito de identificar puntos en común, llegar a acuerdos parciales y generar un posible acuerdo común que surgiera desde los actores involucrados en el conflicto.

Una jornada de catorce horas de negociación entre las partes, dio como resultado el levantamiento inmediato de las medidas de fuerza, la suspensión de la propaganda alusiva al tema y la formación de una comisión especial mixta en el seno de la Asamblea Legislativa (Piszk, 2000: 6). El objetivo de esta Comisión Mixta fue que la misma emitiera su Dictamen sobre un texto alternativo, estableciendo como plazo 150 días legislativos; y estaría integrada por nueve Diputados (4 del PUSC, 3 del PLN, y 2 de los partidos emergentes); siete Representantes del Movimiento Social: (3 del Frente Interno de Trabajadores del ICE, 2 de la Pastoral Social, 1 de las Federaciones Universitarias y 1 de los ambientalistas); un representante del Sector Empresarial, y un representante del Poder Ejecutivo. Asimismo, se acordó retirar del trámite legislativo el Proyecto por un plazo de hasta 150 días, y tramitar dentro de la Asamblea Legislativa el resultado de la comisión mixta; y en lo que corresponde a la Comisión Facilitadora, ésta sería garante de la aplicación del proceso ${ }^{6}$.

El proceso de mediación realizado por la Comisión Facilitadora, cumplió con las características más relevantes que se proponen desde el punto de vista teórico y metodológico en el uso de las técnicas y estrategias de mediación, logró una salida negociada a una escalada de conflicto que había roto con la institucionalidad del sistema político costarricense y restableció el orden y la paz social. El papel de la Comisión Facilitadora y su disposición para llevar adelante un proceso complejo de mediación con la heterogeneidad de actores que caracterizaron el conflicto cumplió con el objetivo de la mediación: que las mismas partes encontraran una solución negociada y viable al conflicto y fue además, la primera experiencia dentro del sistema político costarricense en la que un conflicto rompía la institucionalidad y la paz social.

${ }^{6}$ El texto completo del acuerdo aprobado el 4 de abril de 2000 entre las partes en el proceso de mediación por la Comisión Facilitadora del denominado “Combo Eléctrico” puede ser leído en la siguiente dirección electrónica:

http://wvw.nacion.com/ln_ee/2000/abril/06/opinion6.html Diálogo Nacional. La Nación, 6 de abril de 2000. Consultado el 17 de octubre de 2011. 10:45 a.m. 


\subsection{Caso RITEVE y Movimiento Cívico Nacional: De cómo se organizan y desorganizan las agendas de negociación en el manejo de los conflictos en- tre el Gobierno y los sectores sociales: del 23 al 31 de agosto de 2004}

Durante la Administración Pacheco de la Espriella (2002-2006), se presentó un conflicto que involucró a múltiples actores no gubernamentales, agrupados bajo el denominado Movimiento Cívico Nacional, debido al tema de la revisión técnica vehicular (RITEVE SyC) ${ }^{7}$, que originó un proceso de negociación, en el cual participaron diferentes actores no gubernamentales y representantes del Poder Ejecutivo, entre el 23 y el 31 de agosto del año 2004. Sin embargo, fue necesaria la intervención de representantes de la Defensoría de los Habitantes y de la Conferencia Episcopal para llegar a un acuerdo entre las partes involucradas, originando un proceso de mediación con características muy particulares.

Este proceso de mediación se caracteriza porque un tema único de la agenda política nacional, la revisión técnica vehicular y su alto costo, logró articular una a una, las posiciones de una serie de demandas de otros sectores organizados de la sociedad civil, lo cual provocó una ruptura de la institucionalidad del sistema político costarricense.

En este proceso se identifica un primer momento, en el que los actores son los representantes de los sectores de transportistas de carga pesada (traileros), de taxistas y de empresarios de talleres mecánicos cuyas demandas se orientaron contra el monopolio de RITEVE SyC en la revisión técnica vehicular, y que pretendían la eliminación de dicho monopolio por parte del gobierno; y un segundo momento, cuando el denominado Comité Cívico Nacional, conformado por una coalición de sectores laborales de empleados públicos, de transportistas, de taxistas, de empresarios de talleres mecánicos y de agricultores, apoyados además por sindicatos, estudiantes de universidades estatales y diversos grupos de la sociedad civil, se solidariza con las peticiones del movimiento transportista y realiza nuevas demandas, con el argumento de brindar su apoyo al sector transportista.

La dinámica del conflicto hace que la demanda presentada, en un primer intento de negociación ante Javier Chaves, Ex-Ministro de Obras Públicas y Transportes, por los representantes de Talleres Integrales de Costa Rica (ATICOS), un grupo de

\footnotetext{
${ }^{7}$ RITEVE SyC surge de la alianza estratégica de Transal de Costa Rica con Supervisión y Control de España; ésta última con 20 años de experiencia en la revisión técnica de vehículos y con gran prestigio internacional como una de las compañías más sólidas en su género. Después de un extenso proceso licitatorio iniciado en 1998, la empresa inicia operaciones en julio del 2002 para ordenar y modernizar todo el proceso de revisión técnica con los más altos índices de calidad y tecnología. Asimismo, la revisión técnica vehicular es un procedimiento por el cual según RITEVE: “pretende ayudar a la sociedad costarricense a establecer una cultura de mantenimiento vehicular permanente" como meta a largo plazo, por medio de las normativas estipuladas en: 30184-MOPT Manual de RTV. http://www.rtv.co.cr/ Consultado el 2 de noviembre de 2011. 10:00 a.m.
} 
los traileros y un grupo de taxistas informales, estuviera orientada a la disminución de los estándares de la revisión técnica vehicular y a la eliminación de lo que ellos denominan "el monopolio de RITEVE”, cambie.

De manera simultánea, en apoyo a las protestas por el tema RITEVE, se sumó a las acciones de bloqueos, mediante acciones de paro y huelgas, el denominado Movimiento Cívico Nacional. Este Movimiento estaba conformado por representantes de la Asociación Nacional de Empleados Públicos y Privados (ANEP); Frente Interno de Trabajadores del Instituto Costarricense de Electricidad (FIT), Sindicato de Empleados del Seguro Social, Sindicato Independiente de Trabajadores Estatales Costarricenses (SITEC), Asociación Sindical de Empleados Industriales de las Comunicaciones y la Energía (ASDEICE); Federación de Estudiantes de la Universidad Nacional; y Asociación de Profesores de Segunda Enseñanza (APSE).

El Movimiento Cívico Nacional, además del tema RITEVE, presentó las siguientes nuevas demandas al Gobierno, primera, contra el alto costo de la vida y la disminución del costo de bienes y servicios fundamentales, solicitaron una nueva canasta básica y un aumento salarial para el sector público mayor al 4\% establecido por el gobierno; y en segundo lugar, evitar que el texto del Tratado de Libre Comercio con los Estados Unidos de Norteamérica, Centroamérica y República Dominicana (TLC), ingresara a la corriente legislativa para su discusión y ratificación, bajo el argumento de apoyar al sector transportista.

El primer día del conflicto los actores involucrados paralizaron las principales vías del país y afectaron los servicios públicos, mediante una serie de bloqueos al libre tránsito y acciones de tortuguismo que incidieron en los intereses productivos del país. Al final del día, tanto los representantes del Gobierno como los representantes de los sectores involucrados aceptaron realizar una reunión en la Defensoría de los Habitantes, con el propósito de que el entonces Defensor, José Manuel Echandi Meza, sirviera de garante en el proceso, sin embargo, este diálogo no se realizó ante la negativa de los transportistas de levantar los bloqueos y ante la posición del Gobierno que alegaba la imposibilidad de rescindir el contrato con una empresa española encargada exclusiva de la revisión técnica de vehículos (La Nación, 24 de agosto, 2004).

Durante la madrugada, la acción policial, el uso de gases lacrimógenos y la detención de varias personas hizo que se levantaran la mayor parte de los bloqueos en las vías nacionales, sin embargo, los sindicatos amenazaron con realizar un paro de labores en los servicios públicos de agua, electricidad, telecomunicaciones, hospitales y centros educativos, además de bloquear vías, y convocar a marchas y manifestaciones en todo el país. Ante esta situación, el Defensor de los Habitantes, José Manuel Echandi Meza, realizó una propuesta de tres mesas de negociación separadas para buscar una solución al conflicto entre el gobierno y los actores no gubernamentales involucrados.

Esta propuesta consistía en que una primera mesa abordaría el tema de la revisión técnica, donde estarían los transportistas, el Ministro de Obras Públicas y Transportes y el Contralor General de la República. Una segunda mesa analizaría el 
tema del aumento de salarios al sector público, y participaría el Ministro de Trabajo y los representantes de los sindicatos; y la tercera mesa incluiría el malestar de los sindicatos sobre la aprobación del TLC; con el propósito de reanudar las negociaciones (La Nación, 25 de agosto, 2005).

Aun cuando el Gobierno había expresado en los medios de comunicación nacional su disposición a dialogar, un hecho caracterizaba en esta coyuntura a la Administración Pacheco de la Espriella, por un lado, Alberto Dent Zeledón, Ministro de Hacienda; y Ronulfo Jiménez Morales, Coordinador del Consejo Económico del Gobierno de la República, consideraban imposible ceder ante las demandas del Movimiento Cívico Nacional dada la incapacidad financiera para hacer frente a las solicitudes del Movimiento; y por el otro, un grupo de funcionarios más cercanos al pensamiento del Presidente Pacheco de la Espriella, quienes no consideraban el tema de las sanas finanzas del Estado como la base de la toma de decisiones, con lo cual no creían que estas debían privar y detener el proceso de solución al conflicto, como Ricardo Toledo, que se desempeñaba como Ministro de la Presidencia, o Javier Chaves, Ministro de Transportes, quien había solicitado a la Contraloría General de la República un pronunciamiento sobre la legalidad del contrato con RITEVE, así como la revisión de tarifas de inspección.

Sin embargo, es oportuno indicar que para el Gobierno era necesario encontrar una salida al conflicto e iniciar un proceso de diálogo con el propósito de mantener la estabilidad social, política y económica del país; fortalecer una imagen de su capacidad para resolver conflictos que mejorara su legitimidad; gestionar el libre tránsito como un derecho consignado en la Constitución Política de Costa Rica, y por tanto, hacer respetar la legislación en el país.

Las manifestaciones y bloqueos continuaron a lo largo del país; y una marcha multitudinaria llegó hasta la Asamblea Legislativa en la que participaron los principales sindicatos de las instituciones públicas, estudiantes y transportistas en las que con pancartas y consignas mostraron su molestia al monopolio de la revisión técnica vehicular y al TLC, así como a la política económica del Gobierno.

Las marchas de los sindicatos y estudiantes continuaron, acompañadas de una campaña en los medios de comunicación de propaganda y un llamado a la conciencia por parte de los sectores afectados. Un nuevo intento de diálogo se presentó entre el Gobierno y los representantes del sector transportista, sin embargo, el mismo fracasó debido a que los representantes del transporte pesado solicitaron la devolución de los vehículos que habían sido decomisados durante las acciones policiales; por su parte Javier Chaves había iniciado una acción unilateral para reducir las exigencias de la revisión técnica y flexibilizar los requisitos.

La Defensoría de los Habitantes y la Conferencia Episcopal, en su calidad de mediadores, propiciaron un nuevo encuentro al cierre de la semana, sin embargo, el mismo fracasó y llegó a un punto muerto, y los diferentes sectores amenazaron con iniciar la semana con una protesta de empleados públicos y de los transportistas, con el propósito de realizar un paro de labores y bloqueos en las carreteras.

La semana del 30 de agosto de 2004 inició con nuevas huelgas y una marcha, en esta oportunidad, hacia la Casa Presidencial, sede del Poder Ejecutivo. Sin embargo, 
luego de que los vehículos fueron devueltos en su totalidad a los manifestantes, se planteó la posibilidad de un nuevo diálogo en la Conferencia Episcopal, con la mediación de representantes de la Iglesia Católica y el Defensor de los Habitantes, y ambas partes en conflicto, los representantes del Gobierno y de los transportistas y sindicatos, manifestaron su disposición a dialogar y buscar una solución a las demandas de los diferentes sectores (La Nación, 30 de agosto, 2004).

Los representantes de la Iglesia Católica, José Francisco Ulloa Rojas, Presidente de la Conferencia Episcopal y Monseñor Hugo Barrantes, Arzobispo de San José, así como José Manuel Echandi Meza, Defensor de los Habitantes, representantes legítimos y con un alto grado de credibilidad ante las partes en conflicto, iniciaron el proceso de mediación, como garantes del mismo.

Por su parte los representantes del Gobierno, como de los sectores afectados, acordaron no dar declaraciones a la prensa durante los recesos. Esta decisión cumple, en su esencia, con el hecho de que un proceso de mediación debe de ser voluntario y de común acuerdo entre las partes, al mismo tiempo que facilitaba la comunicación entre las partes para que la información difundida entre los medios de comunicación no provocara desacuerdos durante el proceso.

El proceso de mediación fue convocado para las 2:00 p.m. y se realizó en la Conferencia Episcopal, un lugar neutral y legítimo para las partes en conflicto y se designaron voceros ${ }^{8}$ por parte de ambos grupos; en representación del Gobierno, tres Ministros de Estado, y aun cuando llegaron cerca de treinta personas en representación de los diferentes sectores que se oponían a los diferentes temas de la agenda política nacional, se designaron tres voceros.

Transcurridas doce horas en la reunión entre el Gobierno y el denominado Movimiento Cívico Nacional, los representantes del Gobierno se comprometieron a garantizar un alza salarial adicional del 0,5\% para los empleados públicos; mientras que el otro tema álgido: la posible apertura del mercado de la revisión técnica vehicular quedó en manos de la Contraloría General de la República, el Consejo de Transporte Público y la empresa RITEVE (La Nación, 1 de setiembre, 2004).

Durante el proceso de mediación para encontrar acuerdos que satisfacieran las demandas de los diferentes sectores, se pueden identificar las peticiones iniciales de los actores no gubernamentales: eliminar el monopolio de RITEVE; contra el alto costo de la vida, se solicitaba una nueva canasta básica y una disminución del costo de bienes y servicios fundamentales; aumento salarial para el sector público mayor

${ }^{8}$ Los representantes del Poder Ejecutivo fueron Javier Chaves, Ministro de Obras Públicas y Transporte; Ovidio Pacheco, Ministro de Trabajo y Ricardo Toledo, Ministro de la Presidencia. Por su parte, los voceros de los sectores involucrados en el conflicto fueron tres personas que habían liderado la mayoría de la acciones contra el Gobierno, Eddy González, representante de la Asociación de Talleres Integrales Costarricenses; Marjorie Lizano, en representación de la Cámara Costarricense de Transportistas Unitarios, y el Secretario General de la Asociación de Empleados Públicos (ANEP), Albino Vargas. 
al 4\%, por parte del gobierno y evitar que el texto del TLC ingresara a la corriente legislativa y las propuestas que se presentaron durante el proceso de mediación. Sin embargo, en el transcurso del proceso de mediación, las demandas fueron cambiadas hacia la disminución de los estándares de RITEVE; el estudio de la legalidad del monopolio de RITEVE; la revisión de la canasta básica; el aumento salarial de $2.5 \%$ al sector público por parte del gobierno; así como evitar que el texto del TLC ingresara a la corriente Legislativa; la revisión del cargo del impuesto a los combustibles. Por su parte, los representantes del Gobierno solicitaban el libre tránsito para la reactivación del traslado de productos, mediante el levantamiento de bloqueos; y el respeto a la legislación del país.

El proceso de mediación permitió articular la heterogeneidad de las diversas posiciones e intereses entre las partes en conflicto, y consolidar la voluntad para llegar a un acuerdo que se elaboró desde las propuestas y soluciones que ellas mismas identificaron. El acuerdo que firmaron las partes estaba constituido por los siguientes puntos: el aumento salarial del 0,5\% a los empleados públicos; la revisión de la canasta básica; la revisión del impuesto único a los combustibles; la apertura de espacios de discusión sobre el TLC; la disminución de los estándares de revisión técnica vehicular de RITEVE y la revisión del contrato de RITEVE. Este acuerdo entre el Movimiento Cívico Nacional y los representantes del Poder Ejecutivo, se logró el 31 de agosto del 2004 en la sede de la Conferencia Episcopal de Costa Rica ${ }^{9}$.

El resultado inmediato de este acuerdo fue el reestablecimiento del orden público y la paz social, así como de la institucionalidad dentro del sistema político costarricense, sin embargo, hubo una desintegración del gabinete del Presidente Pacheco de la Espriella, lo cual evidenció la división interna del Poder Ejecutivo en la agenda social y económica, a la que se hizo referencia en líneas anteriores; y su falta de eficiencia en el control y gestión de los asuntos públicos. Alberto Dent, Ministro de Hacienda y Ronulfo Jiménez, Coordinador del Consejo Económico, presentaron su renuncia como resultado de una decisión política de los representantes del Gobierno en el proceso de mediación, que ambos no avalaron desde el punto de vista técnico.

${ }^{9}$ El texto del Acuerdo entre el Movimiento Cívico Nacional y el Poder Ejecutivo del 31 de agosto de 2004 puede ser leído en

http://www.lospobresdelatierra.org/sepamosserlibres/bloqueos0804/acuerdo310804.html

Consultado 4 de noviembre de 2011. 11:45 a.m. 


\subsection{Un caso aparte de mediación: la experiencia del Referéndum ante el TLC con los EE.UU.}

Desde el año 2002 el Gobierno de Costa Rica inició acciones exploratorias para lograr un acuerdo nacional sobre la conveniencia de negociar un instrumento que fomentara el libre comercio con los Estados Unidos de América, además, este fue uno de los proyectos que presentó la Administración Pacheco de la Espriella en su discurso de toma de posesión.

Las negociaciones se iniciaron el 8 de enero de 2003 y el 28 de mayo de 2004, Centroamérica y los Estados Unidos de América firmaron, bajo reserva de aprobación legislativa, un Tratado de Libre Comercio, conocido como TLC.

A diferencia de otros tratados que se habían ratificado en Costa Rica, este Tratado por primera vez incluyó la apertura de servicios de seguros y telecomunicaciones, de gran trascendencia para el país, ya que implican profundos cambios en los servicios del Instituto Nacional de Seguros (INS) y del Instituto Costarricense de Electricidad (ICE). Este tema y otros como los efectos del Tratado en la agricultura, la salud, el medio ambiente y el sector laboral generaron un nutrido debate público. Lamentablemente, alimentado en parte por información confusa y a veces errónea, el debate ha degenerado en una destructiva polarización nacional ${ }^{10}$.

El Ministerio de Comercio Exterior realizó esfuerzos de consulta, información y propaganda entre diferentes sectores, además, se presentaron campañas de los sectores que favorecían el TLC, sin embargo, no se logró generar un acuerdo nacional que hiciera viable al Tratado, y por el contrario se presentaron desacuerdos con los sectores que lo adversaron desde el inicio. Estos sectores y sus acciones colectivas, mediante campos pagados, convocatoria a marchas, llamados a huelgas y manifestaciones, influyeron para que la ciudadanía tomara una posición a favor o en contra, lo cual provocó una polarización inconveniente y maniquea dentro del sistema político costarricense, caracterizada por elementos ideológicos, políticos y de intereses de los diferentes actores y sectores involucrados.

${ }^{10}$ La firma del Tratado por los presidentes sólo implica una aprobación provisional sujeta a la aprobación legislativa. El proceso formal en nuestro país requiere que el Señor Presidente de la República tome la decisión de enviar o no el documento a la asamblea legislativa. Si el documento es enviado, su aprobación o rechazo corresponde a nuestros legisladores. Si la Asamblea Legislativa lo aprueba, el presidente tiene todavía la opción de vetar y la asamblea de rechazar el veto. Tal es nuestro proceso constitucional Informe de la Comisión de Notables. 16 de setiembre de 2005. San José, Costa Rica. El documento completo de la Comisión de Notables, constituida para conocer, estudiar y rendir una opinión de carácter general no vinculante sobre el Tratado de Libre Comercio, y si el Tratado es un instrumento que coadyuve a los objetivos de desarrollo integral del país, se puede leer en la siguiente dirección electrónica:

http://wvw.nacion.com/ln_ee/2005/septiembre/20/informe_tlc.pdf Consultado el 07 de noviembre de 2011. 9:00 a.m. 
Esta división se consolidó aún más con el envío del TLC a la Asamblea Legislativa, por parte del Presidente Pacheco, para su discusión y eventual ratificación por parte del Poder Legislativo. Se incrementaron las marchas pacíficas hacia el Congreso por parte de quienes se oponían al TLC, trabajadores del sector público, sindicalistas, agricultores, educadores y estudiantes gritaban consignas contra el Tratado y hacían llamados a los Diputados para que no ratificaran el tratado comercial. Asimismo, los sectores que apoyaban el TLC, empleados del sector privado y patronos, también realizaron marchas y se pronunciaban por una pronta aprobación del acuerdo en la Asamblea Legislativa.

En la Asamblea Legislativa, la Comisión de Relaciones Internacionales del Congreso definió que se recibirían a unas 30 organizaciones ${ }^{11}$ para que se refieran al Tratado de Libre Comercio (TLC) con los Estados Unidos, sin embargo, durante la Administración Pacheco de la Espriella, no fue posible avanzar ni en la discusión, ni en el trámite legislativo, y el TLC continuaba siendo parte de la agenda política nacional.

El 5 de Febrero de 2006 se realizaron elecciones presidenciales en Costa Rica y resultó electo el candidato del Partido Liberación Nacional, Oscar Arias Sánchez, quien durante su campaña electoral se había pronunciado a favor de la aprobación del TLC. El 7 de Junio de 2006 se reiniciaron las audiencias en la Comisión Legislativa y el 12 de Diciembre de 2006 se aprobó en la Comisión de Asuntos Internacionales, en medio del aplauso de los grupos empresariales y la advertencia de grupos sociales y sindicales de lucha en las calles (Diario de Centroamérica, 14 de Diciembre, 2006)

A partir del momento en que se aprobó el texto del TLC la polarización en los diferentes sectores se acentuó aún más y hubo una serie campañas tanto a favor como en contra. Lo más notorio de este proceso fue que algunas de las instituciones que habían sido protagonistas en los procesos de mediación, tomaron una posición a favor o en contra de este tema de la agenda política nacional y se deslegitimaron para ser mediadores, por lo que se recurrió al Referéndum como forma para tomar una decisión que dirimiera el conflicto entre las dos posiciones.

El 30 de marzo de 2006, Lisbeth Quesada Tristán, la entonces Defensora de los Habitantes, se refirió la TLC en los siguientes términos: "No es un Tratado justo.

${ }^{11}$ Entre los grupos que participarían de las audiencias ante la Comisión de Relaciones Internacionales se encontraban: Comisión de Notables, Consejo de Defensa de la Institucionalidad, Pensamientos Solidarios, Por Costa Rica, ANEP, UPINS, ASDEICE, Magisterio Nacional, Movimiento Solidarista, Conacoop, UCCAEP, Cámara de Agricultura, Cámara de Industrias, CADEXCO, AMCHAM, Cámara de Comercio, Cámara de Productores de Leche, Cámara de Porcicultores, Cámara de avicultores, CRECEX, Cámara de productores de genéricos, Industria textil, UPANACIONAL, Corporación Hortícola Nacional, CONARROZ, Mesa Campesina, LAICA, y Asociación de la Industria Farmacéutica. APSE, Frente Interno de Trabajadores del ICE y representantes del sector campesino. 
Las relaciones de poder están desequilibradas. Este acuerdo es un tratado que no tiene alma”. Así de categóricas fueron las declaraciones de la Defensora de los Habitantes, al referirse al Tratado de Libre Comercio (TLC) entre Centroamérica, Estados Unidos y República Dominicana. Para la Defensoría de los Habitantes si Costa Rica no revisa, cambia y actualiza su modelo de desarrollo, el TLC en vez de convertirse en una herramienta para el mejoramiento y fortalecimiento del país, contribuiría a agudizar los problemas nacionales en el campo social (La Prensa Libre, 31 de marzo, 2006).

De esta forma, después de haber efectuado un análisis sobre el acuerdo comercial y remitirlo a la Comisión de Asuntos Internacionales, la Defensora señaló la necesidad de tomar acciones en aspectos de índole económico, constitucional, medicamentos, telecomunicaciones, seguros y ambiente, entre otros. Con estas declaraciones fue muy clara su posición de oposición al texto del TLC.

Por su parte, la Iglesia Católica también demostró una posición dividida frente al TLC. Desde el inicio de la discusión a nivel nacional sobre el TLC, algunos sacerdotes realizaron campaña en contra o favor del TLC, durante el servicio religioso. En marzo de 2005, con ocasión del Mensaje Pascual "No busquen entre los muertos al que vive”, Monseñor Hugo Barrantes Ureña se refirió a la importancia de desarrollar una Agenda Complementaria al Tratado de Libre Comercio (TLC) de República Dominicana y Centroamérica con los Estados Unidos de América. Al respecto señaló, "sea o no sea aprobado el TLC por nuestros legisladores, urge que ellos tomen las medidas más adecuadas, especialmente a favor de los sectores más vulnerables como son el sector agrícola, el sector laboral, la salud, los recursos naturales y sobre todo la soberanía nacional” (Barrantes, 2005: 12), sin embargo, dado que muchas autoridades de la Iglesia Católica, habían manifestado su posición sobre el TLC, en abril de 2007, Monseñor Barrantes Ureña, manifestó que los sacerdotes no podría utilizar el púlpito para pronunciarse sobre el TLC, e indicó en un segundo momento, que el sacerdote como ministro de la iglesia no debe tomar posición.

De igual forma, los sacerdotes y diáconos de la Diócesis de Alajuela fijaron su posición en contra del TLC, por cuanto el Tratado lesionaría los intereses de los medianos, pequeños agricultores y campesinos, ubicándolos en una posición de desventaja. En un comunicado señalaron, “(...) nos oponemos a la forma en que está planteado el actual proyecto de Tratado de Libre Comercio, no así a una revisión del mismo donde se tome muy en cuenta el respeto y la dignidad de miles de medianos, pequeños agricultores, campesinos que han sido agentes gestores de esto que llamamos democracia costarricense" (Asamblea de Redes Cristianas, 27 de Febrero, 2007).

Dos años antes, las manifestaciones de diferentes jerarcas y representantes de la Iglesia Católica fueron un catalizador para que este actor que había sido históricamente reconocido como neutral e imparcial, y con un alto nivel de credibilidad para llevar adelante un proceso de mediación en los diferentes conflictos que se presentaban dentro del sistema político costarricense, perdiera su papel como un actor neutral e imparcial en el imaginario colectivo. 
Sin embargo, cuando se definió la realización del Referéndum, la Iglesia Católica hizo un llamado a la participación, como ejercicio de la democracia participativa, y posteriormente, los obispos expresaron que no asumirían una posición a favor o en contra a la aprobación del TLC. Aún tratándose de una decisión de mucha importancia para el futuro de la sociedad costarricense, no se trata de un asunto que comprometa el contenido de la fe o de la moral que protege y transmite la Iglesia en fidelidad al Evangelio. La decisión entonces queda reservada al ámbito de la conciencia política de cada miembro de la Iglesia; es a los laicos a quienes nos compete ocuparnos activamente de las realidades temporales para que se conformen a los principios y valores cristianos (Quesada, La Nación, 5 de agosto, 2007).

Un comunicado de la Conferencia Episcopal señaló sobre el tema, reafirmamos nuestro compromiso de iluminar desde el Evangelio y la Enseñanza Social de la Iglesia el ser y el quehacer de la comunidad nacional. No nos corresponde decir si hay que votar sí o no en el referendo, porque "incumbe a las comunidades cristianas analizar con objetividad la situación propia de su país, esclarecerla mediante la luz de la palabra inalterable del Evangelio, deducir principios de reflexión, normas de juicio y directrices de acción según las enseñanzas sociales de la Iglesia ${ }^{12}$, con este documento la Iglesia intentó recuperar su vocación y legitimidad como actor neutral en el proceso del TLC.

En lo que respecta a las universidades públicas, éstas también se pronunciaron en contra del TLC mediante sus Consejos Universitarios. Las instituciones públicas de educación superior fueron consultadas y todas, sin excepción a lo largo del año 2006, manifestaron mediante el pronunciamiento de sus respectivos Consejos Universitarios la oposición para que el Texto del Acuerdo se aprobara.

Los miembros de los Consejos Universitarios argumentaron que el TLC establecía la definición de reglas supranacionales; una transformación profunda en la estructura y funcionamiento del Estado y un golpe a la autonomía del Congreso; la necesidad de que el país logre un crecimiento económico con desarrollo social y que busque resolver sus problemas estructurales, las asimetrías que ponían en

\footnotetext{
${ }^{12}$ El texto completo del Comunicado de la Conferencia Episcopal de Costa Rica en relación con el referendo sobre el TLC puede ser leído en la siguiente dirección electrónica: http://www.fides.org/spa/documents/comunciado_conFerencia_epis._costa_rica.doc Consultado el 9 de noviembre de 2011. 11:15 a.m. Especial atención merece el punto 7 que señala: "Una vez realizado el referendo, exhortamos a todos los sectores a respetar nuestro estado social de derecho y a aceptar el resultado con madurez y serenidad, de tal manera que se evite todo aquello que pueda amenazar la paz social. Corresponderá a todas las fuerzas vivas de la Nación, unirnos en un diálogo transparente y abierto, para consolidar la paz que tiene como nombre el desarrollo. Un desarrollo humano, integral y solidario que propicie el bien común y una sociedad más justa, equitativa e inclusiva”, lo cual implica una muestra hacia la vocación de neutralidad e imparcialidad que había caracterizado a la Iglesia como actor en los procesos de mediación.
} 
desventaja al país; la necesidad de fortalecer la educación como un ventaja competitiva y la necesidad de una agenda complementaria.

El Consejo Universitario de la UCR acordó en sesión No-5058 del martes 28 de marzo de 2006, que se rechazara el proyecto. Por otra parte, el 25 de mayo del 2006, el Consejo Universitario de la Universidad Nacional tomó el acuerdo de oponerse a la aprobación del texto del TLC. El 10 de agosto el Consejo Institucional del Instituto Tecnológico de Costa Rica hace público su pronunciamiento de una firme oposición a la ratificación del actual proyecto y la Universidad Estatal a Distancia da a conocer su opinión al respecto, el 19 de setiembre de 2006, indicando la necesidad de fortalecer el sistema educativo público con la dotación de más recursos y de velar por el mantenimiento y consolidación de niveles educativos con excelencia, para sostener nuestra mayor ventaja competitiva ${ }^{13}$.

Los Rectores de las universidades públicas se reunieron con el entonces Presidente de la República, Oscar Arias Sánchez, en marzo de 2006 y reiteraron el respeto a la institucionalidad democrática y a la Constitución Política, Rodrigo Arias Camacho, Rector de UNED, manifestó, "CONARE no ha mantenido, como órgano, una posición contra el TLC, sino que nos hemos avocado por abrir espacios de diálogo y encontrar fórmulas alternativas para salvar este escollo en la sociedad costarricense”, y también manifestó su preocupación por la búsqueda de fórmulas alternativas que eviten la violencia en la sociedad costarricense. Sin embargo, es oportuno señalar que Eugenio Trejos, Rector del ITCR, presidía el Frente de apoyo a la lucha contra el TLC, un grupo conformado por académicos, intelectuales y políticos, por lo que los otros tres Rectores, asumieron una posición más moderada para resaltar la apertura de espacios de diálogo. Sin embargo, en el imaginario colectivo privó la idea de que todas las universidades públicas mantenían una posición en contra a la ratificación del TLC, principalmente, debido a que los estudiantes de las diferentes universidades representaban un amplio apoyo a las diversas acciones de los grupos organizados en contra el TLC.

En esta confrontación maniquea que caracterizó al sistema político costarricense desde el año 2002, en la cual, tanto actores gubernamentales como no gubernamentales tomaron una posición a favor o en contra de la ratificación del Texto del TLC, surgió la Resolución-E-2007 del Tribunal Supremo de Elecciones, de fecha 11 de abril de 2007, mediante la cual, el TSE autorizó la recolección de firmas para convocar a un referéndum, mediante el cual se aprobaría o no el Texto del TLC.

Posteriormente, el 17 de abril de 2007, el Poder Ejecutivo presentó a consideración de la Asamblea Legislativa el Decreto 33717-MP Iniciativa para la convocato-

${ }^{13}$ El libro de Jorge Enrique Romero Pérez titulado Posición de las universidades públicas en torno al Tratado de Libre Comercio con República Dominicana, Centroamérica y Estados Unidos de América: Acuerdos de los Consejos Universitarios e Institucional, publicado por el Instituto de Investigaciones Jurídicas de la Universidad de Costa Rica recopila los diferentes acuerdos de los Consejos Universitarios tomados respecto al TLC. 
ria a Referéndum para que la ciudadanía apruebe o impruebe el Tratado de Libre Comercio entre República Dominicana, Centroamérica y Estados Unidos, cuyo propósito fundamental fue acelerar el proceso de consulta popular ${ }^{14}$.

Una vez aprobado el Decreto Ejecutivo por la Asamblea Legislativa y entregado al Presidente del TSE, Luis Antonio Sobrado, expresó que la decisión del futuro del TLC en un referéndum, es un mecanismo que evitaría la confrontación social y la violencia. "El magistrado electoral, en el momento en que toma una decisión como la del referendo, lo hace sobre una base jurídica, pero lo hace también sobre un análisis de cómo el referéndum está previsto y concebido para darle una salida institucionalizada a situaciones de bloqueo legislativo y respecto de las cuales existe alta crispación pública y donde corre riesgo la paz social”, y reafirmó, "el referendo no es una ocurrencia del Tribunal Supremo de Elecciones, es un instrumento previsto para darle salida a situaciones de crisis como la que vivimos" (La Nación, 27 de abril, 2007). El 12 de julio de 2007 el TSE realizó la convocatoria para realizar el referéndum sobre el TLC el 7 de octubre de ese mismo año, y los electores definirían sí o no, a la pregunta establecida por esta misma institución: “¿Aprueba usted el "Tratado de Libre Comercio República Dominicana, CentroaméricaEstados Unidos” (TLC), expediente legislativo n. ${ }^{\circ} 16.047$, según el texto acordado por la Comisión especial de Asuntos Internacionales y comercio Exterior de la Asamblea Legislativa, publicado en el Alcance $n .^{\circ} 2$ de La Gaceta n. ${ }^{\circ} 19$ del 26 de enero del 2007?”

En el discurso de convocatoria el Magistrado Sobrado solicitó a los líderes políticos y sociales que asumieran con prudencia y sensatez el debate previo a las votaciones; y pidió madurez, compromiso cívico y respeto a las reglas de conducta política. Además, solicitó a los líderes del sí y del no evitar la desinformación, las descalificaciones de la institucionalidad electoral, los llamamientos a no votar y el establecimiento de condiciones como requisito para participar o reconocer el resultado. A la ciudadanía la exhortó a votar en la medida en que recordó que los ciudadanos son los protagonistas del proceso.

Durante el tiempo que transcurrió hasta la celebración del referéndum sobre el TLC se presentó un intenso y diverso activismo por parte de la ciudadanía, los diferentes sectores tomaron conciencia y comprendieron la importancia de este proceso, de forma que participaron activamente en la consulta.

Se organizó un movimiento social y político a favor del sí, denominada "Alianza Ciudadana por el Sí”, que incluía representantes de diferentes partidos políticos, y

${ }^{14}$ Una serie de documentos y artículos de periódico fueron recopilados en relación con el Referéndum sobre el TLC por la Biblioteca Monseñor de la Asamblea Legislativa. Estos pueden ser revisados en la dirección electrónica http://www.asamblea.go.cr/Centro_de_informacion/Centro_Dudas/Lists/Formule\%20su\%20 pregunta/Attachments/274/Referendun.pdf Consultado el 17 de noviembre de 2011. 9:15 p.m. 
de diversos sectores de la sociedad civil, y realizaron una campaña informativa sobre los contenidos del Tratado. Su principal objetivo fue la ratificación del TLC.

La pluralidad y diversidad de sectores que estaban en contra de la aprobación del Tratado se fusionó en el llamado "Movimiento Patriótico contra el TLC” y surgió de manera espontánea. Estaba conformado por organizaciones campesinas, cooperativas y comunales, grupos ecologistas, culturales y religiosos, miembros de partidos políticos y académicos, líderes políticos y sindicales; y se unieron por lo que conceptualizaron la defensa de la Patria, realizando varias manifestaciones y movilizaciones para demostrar su oposición.

Finalmente, se realizó el Referéndum del TLC bajo la supervisión del Tribunal Supremo de Elecciones, lo que consolidó su legitimidad y credibilidad en esta coyuntura, a pesar de las críticas de algunos dirigentes políticos. El resultado de la votación en el Referéndum favoreció al sí con un 51,6\% de los votos, frente a un $48,4 \%$ de votos que apoyaron el no ${ }^{15}$.

Como resultado de la elección del Referéndum para solucionar la polarización que se había generado en torno al tema de la aprobación o no del TLC, el Tribunal Supremo de Elecciones, como institución representativa de la democracia costarricense fue sometido a una prueba de legitimidad, credibilidad e imparcialidad. Aún cuando no se haya presentado un proceso de mediación, no cabe la menor duda que el TSE actúo como un tercer imparcial que encontró la alternativa para generar la mejor decisión dadas las circunstancias de polarización en este tema de la agenda política nacional y como resultado, consolidó su credibilidad en la gestión de estos procesos, a pesar de que su legitimidad fue cuestionada por algunos sectores luego de realizar el Referéndum.

Asimismo, se aprobó la discusión de trece Proyectos de Ley correspondientes a la Agenda de Implementación del TLC, que tendrían que ser discutidos del 8 de Octubre de 2007 al 11 de Noviembre de 2008, y se consolidó el respeto a la democracia participativa por un amplio sector de la ciudadanía costarricense, así como el respeto a nuevas formas de asociación.

La realización del Referéndum fue una oportunidad para buscar una solución democrática y participativa a un conflicto que tenía cinco años de estar en la agenda política nacional, y dada la toma de posición de otros actores institucionales que habían sido garantes de los procesos de mediación, la figura del referéndum y la supervisión por parte del Tribunal Supremo de Elecciones, permitió respetar la voluntad de una mayoría de ciudadanos.

${ }^{15}$ Datos tomados del registro de resultado definitivos del referéndum de la página web del Tribunal Supremo de Elecciones http://www.tse.go.cr/ref/ref_def/pais.htm Consultado el 18 de noviembre de 2011. 8:45 a.m. 


\section{Reflexión final}

Los procesos de mediación, como método para la resolución alternativa de conflictos, representan una oportunidad para buscar soluciones creativas y devolver a las partes en conflicto su capacidad para que ellas mismas gestionen sus conflictos.

Aun cuando algunos procesos de mediación son conceptualizados como un proceso entre dos partes individuales, este trabajo ha demostrado que, desde el punto de vista de la Ciencia Política, es posible resolver conflictos sobre temas de la agenda política nacional en el marco del sistema político costarricense y con varios actores que han asumido posiciones que parecen no tener ningún punto de encuentro.

Los representantes de instituciones que son una representación de la democracia costarricense, como el Tribunal Supremo de Elecciones, la Defensoría de los Habitantes, la Conferencia Episcopal de la Iglesia Católica y el Consejo Nacional de Rectores, tradicionalmente han sido reconocidos como actores legítimos e imparciales en la facilitación de un proceso de mediación. Sus características de neutralidad e imparcialidad, no sólo son aspectos esenciales en el desarrollo de la mediación, sino que la credibilidad de estas instancias y sus representantes, también son garantes de un proceso de mediación mientras mantengan su vocación de neutralidad, es reconocida por la ciudadanía.

La tradición democrática y de justicia social que ha caracterizado el sistema político, así como el respeto a la institucionalidad, hace que se presenten formas novedosas y creativas en la búsqueda de soluciones a los conflictos coyunturales que se dan frente a una política pública, y que permite la realización de acciones colectivas de grupos de interés, grupos de presión o movimientos sociales.

La escalada del conflicto entre las diferentes posiciones de los sectores que toman una posición a favor o en contra, ante la elaboración de una política pública, genera una dinámica interesante en los procesos de mediación y las negociaciones del sistema político costarricense. Por un lado, el proceso de toma de decisiones de las autoridades gubernamentales no es público, sino que los grupos de interés y grupos de presión desarrollan acciones colectivas, que pueden romper el orden y la institucionalidad del sistema político; por otro, el hecho de que esta ruptura del orden institucional no es parte del proceso de socialización de los costarricenses, hace que se generen formas creativas en la solución de conflictos mediante procesos de mediación, liderados por representantes de instituciones que gozan de un alto nivel de credibilidad.

En el caso de la Comisión Facilitadora para resolver el conflicto del denominado Combo Eléctrico, en el año 2000, su disposición para propiciar un encuentro sin restricciones entre las partes y coadyuvar a la búsqueda de un acuerdo, cumplió con todos los requisitos establecidos, desde el punto de vista teórico y metodológico de un proceso de mediación. La búsqueda de un lugar neutral, el Tribunal Supremo de Elecciones; el establecimiento de reglas del juego claras; la designación de voceros; la posibilidad de realizar reuniones por separado entre los actores involucrados; y 
sobre todo, la imparcialidad y credibilidad de las personas que guiaron el proceso, fueron elementos determinantes para llegar a un acuerdo.

Asimismo, la disposición al diálogo y la voluntad de realizar una reunión de hasta doce horas de duración, en el marco del Conflicto con RITEVE, durante la Administración Pacheco de la Espriella, permitió que los representantes de la Iglesia Católica, José Francisco Ulloa Rojas, Presidente de la Conferencia Episcopal y Monseñor Hugo Barrantes, Arzobispo de San José, así como José Manuel Echandi Meza, Defensor de los Habitantes, representantes legítimos y con un alto grado de credibilidad ante las partes en conflicto, iniciaran el proceso de mediación, como garantes del mismo. Su disposición a realizar este proceso permitió reestablecer el orden institucional, aún cuando el mismo proceso evidenció la falta de claridad en la gestión y resolución de conflicto del Poder Ejecutivo, donde las decisiones de carácter político frente a las decisiones de carácter técnico, tuvieron un alto costo para la Administración Pacheco, y fue un indicador de las diferencias entre quienes coordinaban la parte económica y social en durante esta gestión.

Es importante tomar en consideración que tanto en el Combo Eléctrico, como el caso RITEVE, el mayor problema que afectó el orden institucional, fue que las protestas y manifestaciones realizadas, recogieron el descontento que había acumulado la ciudadanía por varios años y por diversas razones.

Además, en ambos casos, así como en la convocatoria al Referéndum sobre el TLC, aún cuando son temas que por su trascendencia, se podrían catalogar como un único tema de la agenda política nacional, hacen que la dinámica de los actores no gubernamentales que se van sumando al conflicto lleguen con nuevas demandas, lo cual complica aún más el proceso para el Gobierno de turno. Asimismo, es claro que en los tres casos presentados en este trabajo, la falta de información y formación de opinión en forma clara y transparente respecto a estos temas, hace que se empiecen a desarrollar argumentos de carácter político e ideológico que abonan el terreno para una escalada irracional del conflicto. Las informaciones confusas y poco precisas sobre los argumentos técnicos que hacen al Poder Ejecutivo tomar decisiones para la elaboración de las políticas públicas, aunado a la desconfianza que ha sufrido la clase política en los últimos años, propician el ambiente para un conflicto social, aún cuando el Gobierno insista en su disposición al diálogo y a la apertura de canales de comunicación, cuando se presentan tales conflictos.

No cabe la menor duda que dentro del sistema político costarricense existe una mayor capacidad de organización y articulación por parte de los sectores y movimientos sociales, y esto quedó demostrado a partir del Combo Eléctrico, se validó con el caso RITEVE y, las acciones colectivas que se presentaron durante los cinco años que estuvo el tema del Texto de Tratado de Libre Comercio con los Estados Unidos de América, Centroamérica y República Dominicana, conocido como TLC. En los procesos estudiados quedó demostrado que existe una verdadero reconocimiento de las partes que permiten la maduración del conflicto y llegar a fórmulas de acuerdo para restablecer la institucionalidad y la paz social que han caracterizado el sistema político costarricense, y mantener los niveles de credibilidad ante el ciudadano. 
En cuanto a las personas que actúan como mediadores en representación de las instituciones reconocidas como legítimas y neutrales, existe la suficiente experiencia, sin embargo, esta no se ha sistematizado en cuanto a la metodología de trabajo para garantizar un exitoso proceso de mediación. Los representantes del Tribunal Supremo de Elecciones, la Defensoría de los Habitantes, la Iglesia Católica y el Consejo Nacional de Rectores (CONARE), han demostrado que son personas que son capaces de devolver a las partes en conflicto su capacidad negociadora para que ellas mismas recuperen su capacidad de gestionar el conflicto, mediante el acuerdo de soluciones inteligentes y beneficiosas.

También han demostrado ante la ciudadanía las cualidades que caracterizan un mediador eficaz, tales como la absoluta imparcialidad, mediante la credibilidad y confianza que generan antes y durante el proceso; la confiabilidad y habilidad para motivar a las personas a buscar soluciones creativas; su capacidad para escuchar y de entender los hechos; su capacidad de escuchar y la competencia para resolver problemas, entre otras.

De esta manera, han actuado desde el no poder, no analizan, no juzgan ni sancionan; facilitan a las partes en conflicto la posibilidad de encontrar por sí mismas, sus propias y originales soluciones y han comprendido que los acuerdos son herramientas para avanzar en el proceso de reconcialiación de las propias capacidades para identificar una solución a los problemas.

Los procesos de mediación desarrollados en el marco del sistema político costarricense, aun cuando fueron referentes a conflictos coyunturales que tuvieron por la escalada de conflicto de alcance nacional, lograron reestablecer la tradición democrática, el respeto a la institucionalidad y el orden constitucional, mediante el logro de acuerdos que fueron operacionalizados y llevados a la práctica en un segundo momento, lo cual evidencia, el carácter voluntario y pacífico de los procesos de mediación en Costa Rica.

\section{Referencias bibliográficas}

Asamblea de Redes Cristianas. "Fuerte debate social por el Tratado de Libre Comercio". 27 de Febrero de 2007. Documento sin notas de alcance.

Barrantes, Hugo. (2005). Mensaje Pascual: No busquen entre los muertos al que vive. Editorial Conferencia Episcopal de Costa Rica. San José.

Butts Griggs, Thelma, et.al. "Intervenciones de mediación”. En: Munduate Jaca, Lourdes y Francisco José, Medina Díaz. (2009): Gestión del Conflicto, Negociación y Mediación. Pirámide, Madrid.

Duverger, Maurice. (1988). Instituciones políticas y derecho constitucional. Ariel. Madrid. 
González, Gerardo. "Defensor presenta propuesta de negociación en conflicto con transportistas”. En: La Nación (Periódico). Miércoles 25 de agosto de 2004.

Gudiño, Arturo. “TSE afirma que referendo puede evitar confrontación social”. En: La Nación (Periódico). Viernes 27 de abril de 2007.

Herrera Ulloa, Mauricio. "Pasó Plan ICE”. En: La Nación (Periódico). Martes 21 de marzo de 2000. Jueves 23 de marzo de 2000.

Lunes 27 de marzo de 2000.

Loaiza, Vanessa y Esteban Oviedo. “Gobierno solo empeñó palabra en salarios. En: En: La Nación (Periódico). Miércoles 1 de setiembre de 2004.

Morris Gray, Krissia. "Defensoría afirma que TLC carece de alma”. En: La Prensa Libre. (Periódico). Viernes 31 de marzo de 2006)

Mainwaring, Scott \& Mathew Shugart Soberg. En: "Presidencialismo y democracia en América Latina: revisión de los términos del debate”. En: Mainwaring, Scott y Mathew Shugart Soberg. (2002): Presidencialismo y democracia en América Latina. (ed.) Paidós, Buenos Aires.

Meny Ives y Jean-Claude Thoenig. (1992): Las políticas públicas. Ariel. Barcelona. Piszk, Sandra. (2000): Informe Anual de Labores 1999 - 2000. Defensoría de los Habitantes. San José. http://www.dhr.go.cr/informe.html Consultada el 17 de octubre de 2011. 10:00 a.m.

Quesada, José Ramón. “La Iglesia y el TLC”. En: La Nación (Periódico). Domingo 5 de agosto de 2007.

Redacción. "Pacheco dice "es doloroso" lo que sucede por huelga de transporte”. En: La Nación (Periódico). Martes 24 de agosto de 2004.

----------- "Transportistas, sindicatos y gobierno volverán hoy al diálogo”. En: La Nación (Periódico). Lunes 30 de agosto de 2004.

--"Luz verde del Congreso a TLC con EE.UU. "agita las aguas””. En: Diario de Centroamérica. Edición No. 954. Jueves 14 de diciembre de 2006.

Romero Pérez, Jorge Enrique. (2007). Posición de las universidades públicas en torno al Tratado de Libre Comercio con República Dominicana, Centroamérica y Estados Unidos de América: Acuerdos de los Consejos Universitarios e Institucional. Instituto de Investigaciones Jurídicas, Universidad de Costa Rica, San José.

Sobrado González, Juan José (2007): "Primera Experiencia del Referéndum en Costa

Rica: Regulación y Alcances”. Revista de Derecho Electoral. No. 4. Segundo Semestre 2007. Tribunal Supremo de Elecciones. San José, Costa Rica.

Subirats, Joan. (1992): Análisis de las Políticas Públicas y eficacia en la administración. Ministerio para las Administraciones Públicas, Madrid.

Torres-Rivas, Edelberto. "El desarrollo democrático a la luz de un lustro de paz: un balance preliminar”. En: Zamora, Rubén et.al. (2002): A cinco años de la firma de la paz en Guatemala: un balance crítico. Facultad Latinoamericana de Ciencias Sociales (FLACSO). Ciudad de Guatemala.

Vinyamata Camp, Eduard. (2003): Aprender Mediación. Paidós. Barcelona. 
Zartman, William and Maureen R. Berman. (1982): The Practical Negotiator. New Haven and London Yale University Press, Massachusetts.

Zartman, William. (1986). "Ripening Conflict, Ripe Moment, Formula and Mediation, In: Bendahmane, Diane B. and W. Mc-Donald. Perspectives on negotiation: four case studies and interpretations. Center for the Study of Foreing Affairs. Foreing Service Institute U.S. Department of State. 